\title{
An unusual variant of the atlantomastoid muscle
}

\author{
N.O. Blackwood ${ }^{1}$, Ł. Olewnik², G.P. Georgiev³, G. Wysiadecki' ${ }^{4}$ A. Aysenne, \\ J. Iwanaga ${ }^{1,5}$, R.S. Tubbs ${ }^{1,5-8}$ \\ ${ }^{1}$ Department of Neurosurgery, Tulane University School of Medicine, New Orleans, LA, United States \\ 2Department of Anatomical Dissection and Donation, Chair of Anatomy and Histology, \\ Medical University of Lodz, Poland \\ ${ }^{3}$ Department of Orthopaedics and Traumatology, University Hospital Queen Giovanna - ISUL, \\ Medical University of Sofia, Bulgaria \\ ${ }^{4}$ Department of Normal and Clinical Anatomy, Chair of Anatomy and Histology, Medical University of Lodz, Poland \\ ${ }^{5}$ Department of Neurology, Tulane University School of Medicine, New Orleans, LA, United States \\ ${ }^{6}$ Department of Anatomical Sciences, St. George's University, St. George's, Grenada, West Indies \\ 'Department of Structural and Cellular Biology, Tulane University School of Medicine, New Orleans, LA, United States \\ ${ }^{8}$ Department of Neurosurgery, and Ochsner Neuroscience Institute, Ochsner Health System, \\ New Orleans, LA, United States
}

[Received: 20 July 2021; Accepted: 3 November 2021; Early publication date: 16 November 2021]

\begin{abstract}
Knowledge of anatomical variations can be of use to clinicians and surgeons when, for example, viewing images of a patient or performing operations. Such knowledge can minimise the risk of iatrogenic complications. Herein, we present a case of a variant atlantomastoid muscle. The muscle was identified on the left side in an adult cadaver. The muscle's measurements and anatomical relationships are presented as well as a review of salient literature. We hope that increased knowledge of anatomical variants in the suboccipital region can improve patient care. (Folia Morphol 2023; 82, 1: 211-215)
\end{abstract}

Key words: anatomical variation, atlantomastoid muscle, suboccipital muscles, suboccipital region

\section{INTRODUCTION}

The atlantomastoid muscle is a muscle variant in the suboccipital region. It originates from the transverse process of the atlas and inserts on the posterior aspect of the mastoid process of the temporal bone $[2,5,6,8,9,11]$. It is innervated by the dorsal ramus of $\mathrm{C} 1$ and supplied by the occipital artery [9]. The clinical relevance of this muscle variant arises from its proximity to important cervical and suboccipital neurovasculature, including the occipital artery, the vertebral artery, and the dorsal ramus of $C 1[2,4$, $6,9]$. This paper reports a case of a variant atlantomastoid muscle found in a cadaver and describes its relationships to surrounding anatomical structures.

\section{CASE REPORT}

During the routine dissection at the Tulane University School of Medicine, New Orleans, Louisiana, United States of an 88-year-old at death male cadaver, a variant muscle of the suboccipital region was identified. This finding was determined to be the atlantomastoid muscle (Figs. 1, 2). The muscle joined the posterolateral aspect of the transverse process of the atlas to the mastoid part of the temporal bone medial to the mastoid notch. The muscle was more or less positioned halfway between the mastoid notch laterally and the occipitomastoid suture medially. Using microcallipers (Mitutoyo, Japan) to measure the muscle, it was found to be $1.1 \mathrm{~cm}$

Address for correspondence: J. Iwanaga, DDS, PhD, Department of Neurosurgery, Tulane Centre for Clinical Neurosciences, Tulane University School of Medicine, 131 S. Robertson St. Suite 1300, New Orleans, LA 70112, United States, tel: 5049885565, fax: 5049885793, e-mail: iwanagajoeca@gmail.com This article is available in open access under Creative Common Attribution-Non-Commercial-No Derivatives 4.0 International (CC BY-NC-ND 4.0) license, allowing to download articles and share them with others as long as they credit the authors and the publisher, but without permission to change them in any way or use them commercially. 


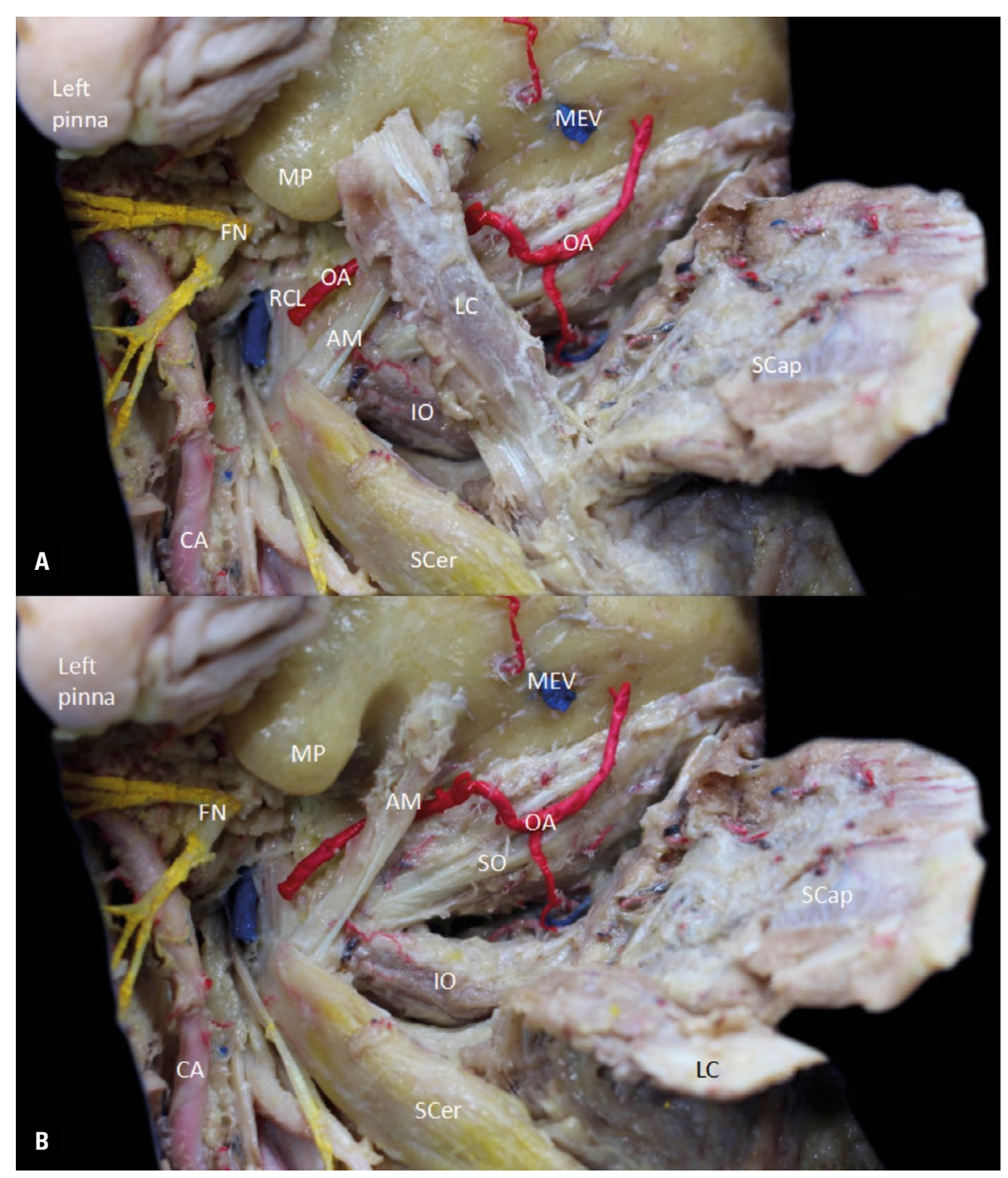

Figure 1. A. Left atlantomastoid muscle (AM) as described in the present case report. The upper fibres of the muscle are covered here by the attachment of the longissimus capitis muscle (LC) onto the mastoid process (MP); B. Following the reflection of the LC; CA - external carotid artery; $\mathrm{FN}$ - facial nerve; 10 - obliquus capitis inferior muscle; $\mathrm{MEV}$ - mastoid emissary vein; $\mathrm{OA}$ — occipital artery; $\mathrm{RCL}$ - rectus capitis lateralis; SCap — splenius capitis muscle; SCer — splenius cervices muscle; SO — obliquus capitis superior muscle.

in width and $5.3 \mathrm{~cm}$ long. Its innervation was via a small branch from the suboccipital nerve. Its blood supply was via a branch from the occipital artery, which travelled deep to the muscle at the junction of its upper third to lower two thirds. The muscle was deep to the longissimus capitis and splenius capitis muscles and in the same plane as the suboccipital triangle muscles, e.g. obliquus capitis superior muscle. As the muscle attached onto the mastoid part of the temporal bone, it was positioned just posterior to the digastric muscle's posterior belly. The mastoid emissary vein was seen medial to the muscle's attachment onto the temporal bone (Fig. 3). No atlantomastoid muscle was identified on the right side, and no additional anatomical variations were observed on the left side. No medical or surgical history of the cadaver was available.

\section{DISCUSSION}

The atlantomastoid muscle has been reported through primary observation in 7 studies (Table 1). The first report was in a description by Winslow in 1732 [11]. Bankart published observations of 158 cadavers in 1869 and included reports of the muscle variant [1]. Gruber [2] remarked on it in a report on 50 cadavers in 1876. Knott [5] studied the atlantomastoid muscle in 33 cadavers. Le Double [6] published a summary of previous reports of the atlantomastoid muscle in addition to his own observations of this muscle in 52 cadavers. Mori [9] published a study of 


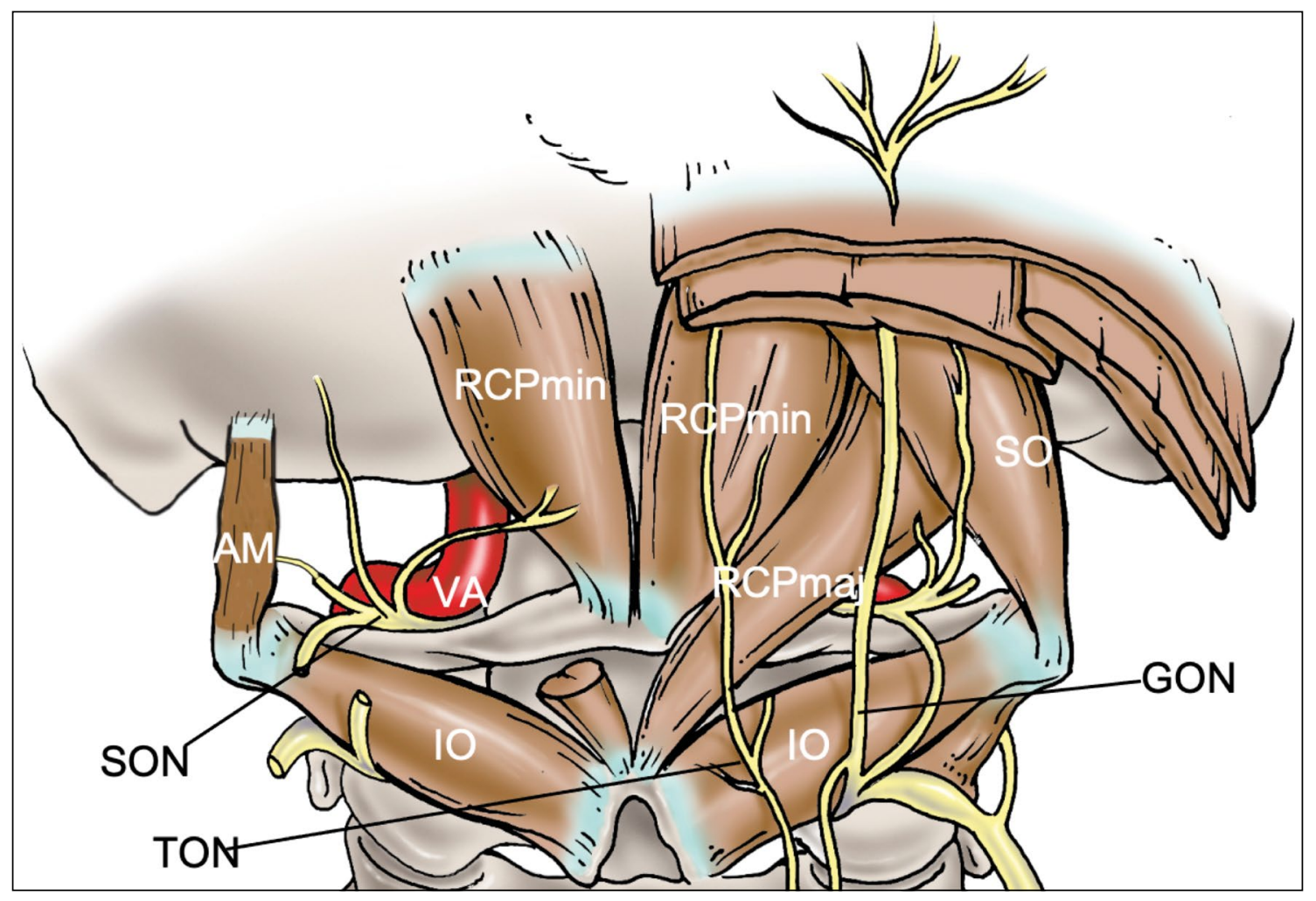

Figure 2. Schematic drawing of the atlantomastoid muscle (AM) noting its innervation from a small branch of the suboccipital nerve (SON). For clarity, the rectus capitis lateralis, which was anterior to the AM is not shown but in this view would have been just anterior to the AM; $\mathrm{RCPmin} \mathrm{—} \mathrm{rectus} \mathrm{capitis} \mathrm{posterior} \mathrm{minor;} \mathrm{RCPmaj} \mathrm{—} \mathrm{rectus} \mathrm{capitis} \mathrm{posterior} \mathrm{major;} \mathrm{SO} \mathrm{—} \mathrm{obliquus} \mathrm{capitis} \mathrm{superior} \mathrm{muscle;} 10$ — obliquus capitis inferior muscle; VA — vertebral artery; greater GON — occipital nerve; TON — third occipital nerve.

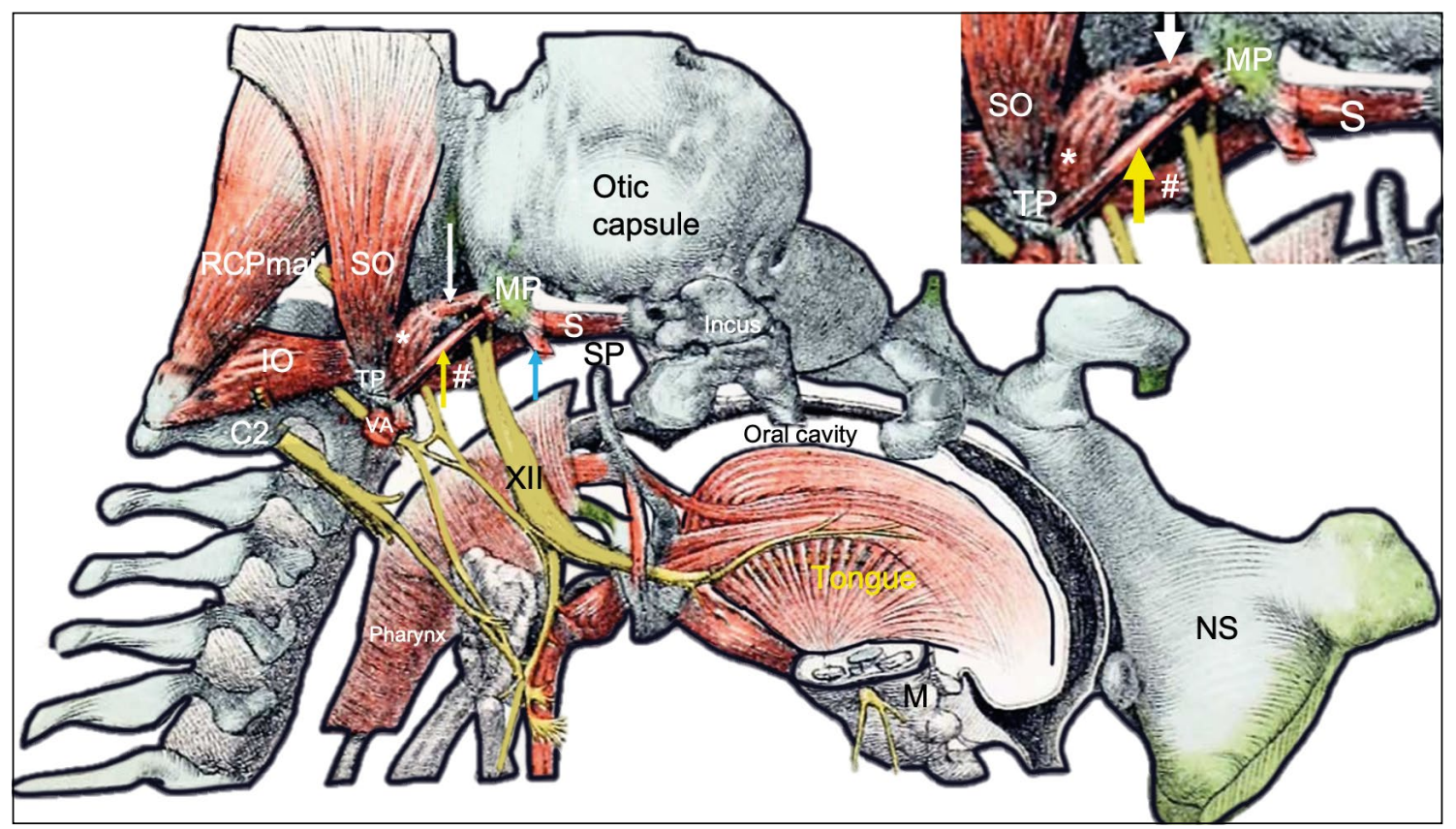

Figure 3. Schematic drawing of a $21 \mathrm{~mm}$ long embryo. The atlantomastoid (yellow arrow) and related muscles are noted. Related muscles include the occipitomastoid (white arrow), rectus capitis lateralis $\left({ }^{*}\right)$, rectus capitis anterior (\#), posterior belly of the digastric (blue arrow), stapedius (S), obliquus capitis inferior (IO), obliquus capitis superior (SO), and the rectus capitis posterior major (RCPmaj). Bony landmarks include the transverse process (TP) of the C1, styloid process (SP), and the C2 vertebra (C2). The cut vertebral artery (VA) and hypoglossal nerve (XII) are also shown. Anteriorly, the mandible (M) and nasal septum (NS) are seen; MP — mastoid process. (After Lewis, 1920 [8]). The inset is a zoomed in view of the region of the atlantomastoid muscle and its surrounding anatomy. 
Table 1. Sex, side, and country of reports of the atlantomastoid muscle

\begin{tabular}{lcccc}
\hline & Number & Sex & Laterality & Country \\
\hline Gruber [2] & $11 / 50$ & $45 \mathrm{M} / 5 F^{*}$ & $4 \mathrm{~B} / \mathrm{L} 7$ & Germany \\
Knott [5] & $4 / 33$ & Unknown & Unknown & Unknown \\
Le Double [6] & $9 / 52$ & $6 \mathrm{M} / 3 \mathrm{~F}$ & $4 \mathrm{~B} / \mathrm{L} 2 / \mathrm{R} 4$ & France \\
Mori [9] & $14 / 54$ & Unknown & 5B/L4/R5 & Japan \\
\hline
\end{tabular}

$\mathrm{M}$ - males; $\mathrm{F}$ - females; $\mathrm{B}$ - bilateral; $\mathrm{L}$ - left side only; $\mathrm{R}$ - right side only. The number column is the reported number of muscles found out of the total number of cadavers dissected. Note that LeDouble states that he identified the atlantomastoid muscle in 9 specimens, he goes on to describe 4 of these as being found bilaterally, and 2 on left sides only and 4 on right sides only which adds up to ten. ${ }^{*}$ Also note that although Gruber listed that he dissected 45 males and 5 females, we are not told the sex of the

11 specimens found to have the muscle and that only LeDouble specified that 6 males and 3 females were found to have the muscle.

this variant in 54 Japanese cadavers in 1964. To our knowledge, since Mori's study, no additional reports of this muscle have been published. There has been no published cadaveric image of the atlantomastoid muscle. Therefore, the current case is of archival value.

Four studies provide information about the frequency of the atlantomastoid muscle. Gruber [2] reported finding the muscle variant in 11 (22\%) of 50 cadavers and 15 of 100 sides (15\%). Knott [5] observed it in four of $33(12.1 \%)$ subjects. Le Double [6] observed the atlantomastoid muscle in 9 of 52 (17.3\%) cadavers. Mori [9] discovered the muscle in $14(25.9 \%)$ of 54 cadavers and $19(17.6 \%)$ of 108 sides. Overall, the muscle has been reported in $15.7 \%$ (49/312) of sides and $20.1 \%$ (38/189) of cadavers [7].

Questions regarding sex, age, and nationality/ /ethnicity differences in the atlantomastoid muscle frequency, along with differences between sides, remain valid. Of the 7 primary reports of the muscle, only 4 provided quantitative frequency data $[2,5,6,9]$. Only the study of 54 Japanese cadavers provided information about the population of origin for samples [9]. LeDouble's report was the only one to relate frequency to sex [6]. Only 3 studies reported laterality differences in the frequency of the atlantomastoid muscle $[2,6,9]$. No observations of age differences in the atlantomastoid muscle among specimens have been published.

The muscle has been reported in the gorilla, chimpanzee, and seminopithecus [2, 10]. Although the exact function is unknown, we posit that it could, in concert with other regional muscles, rotate the skull ipsilaterally.

Most have described the atlantomastoid muscle as attaching onto the mastoid process of the temporal bone. However, as seen in our case, Gruber [2] did depict 1 case of a more medial attachment of the muscle away from the mastoid process. These attachments of the muscle seem to be a rare variation.

\section{Classifications}

Based on reports in the literature and our present case, the atlantomastoid can be classified into two broad categories - attachment onto the mastoid process or attachment to surrounding parts of the temporal bone. We would propose these be considered as types 1 and 2, respectively, with the later, as seen in our present case, being much less common. Within these two categories are smaller variations. The muscle can be anterior or posterior to the rectus capitis lateralis [2]. Gruber [2] added that the atlantomastoid might have accessory slips with the middle scalene, levator scapulae, splenius capitis, or longissimus cervicis muscles. Mori [9] also added that the muscle can have slips to the longissimus capitis, transverse process of C2, and splenius capitis muscle. We propose that such additional slips could be classified as types $1 \mathrm{a}$ or $2 a$ depending on the primary bony attachment, i.e. on or adjacent to the mastoid process.

\section{Embryology}

The development of the muscles of the suboccipital region has not been well studied. Mori [9] suggested that the atlantomastoid muscle, obliquus capitis superior, and longissimus capitis muscles might share the same embryological derivation due to their innervation by the suboccipital nerve. Lewis [8] described and depicted the atlantomasotid muscle in a $21 \mathrm{~mm}$ embryo as being attached to the mastoid blastema and as being long and slender (Fig. 3). He also described the adjacent occipitomastoid (Fig. 3) and believed it might be related to the intertransversarii muscles although he also suggested this muscle could be derived from the pharyngeal arches. Both muscles were considered rudimentary muscles by Lewis who also stated they were not found in adults.

\section{Clinical/Surgical applications}

We hope that increased knowledge of anatomical variants in the suboccipital region can improve patient care. Repeated observations on anatomical variations deepen existing knowledge, can help to overcome the subjective aspect in the description made by individual researchers, and can also be useful for clinicians in their daily practice [12]. Procedures that might encounter or specialities that need to know details 
about this muscle include neurosurgical approaches to the skull base such as suboccipital craniectomy and exposure of the occipital artery for occipital artery to posterior cerebral artery bypass and interventional procedures that target the occipital region in treating patients with, for example, pain related to muscle spasm or muscle compression of surrounding nerves, i.e. occipital neuralgia migraine and require botulinum toxin injection to the suboccipital musculature. Lastly, although small, the atlantomastoid muscle, with the continued improvement in imaging techniques, e.g. magnetic resonance imaging might be appreciated by radiologist viewing the skull base. Therefore, knowledge of the atlantomastoid can improve interpretation of images and prevent misdiagnosis if it is identified.

\section{CONCLUSIONS}

We present a variant of the atlantomastoid muscle. Based on our proposed classification of the muscle, this would be a type 2 muscle. Such a muscle attaching medial to the mastoid notch might be encountered during craniotomies in this region. For example, this is the location of a retrosigmoid craniotomy for access to the cerebellopontine angle. Additionally, surgeons who are localising the occipital artery would need to know that the atlantomastoid muscle, when present, can travel superficially to the artery and lie deep to the longissimus capitis muscle, which normally covers it posteriorly.

\section{Acknowledgements}

The authors sincerely thank those who donated their bodies to science so that anatomical research could be performed. Results from such research can potentially increase humankind's overall knowledge that can then improve patient care. Therefore, these donors and their families deserve our highest gratitude [3].

Conflict of interest: None declared

\section{REFERENCES}

1. Bankart J, Pye-Smith P, Phillips J. Notes of abnormalities observed in the dissecting room during the winter sessions of 1866-7 and 1867-8. Guy's Hospital Reports. 1869; 14(3): 436-455.

2. Gruber W. Über den Musculus atlantico-mastoideus. Arch Anat Physiol Wissen Med. 1876: 733-738.

3. Iwanaga J, Singh V, Ohtsuka A, et al. Acknowledging the use of human cadaveric tissues in research papers: Recommendations from anatomical journal editors. Clin Anat. 2021; 34(1): 2-4, doi: 10.1002/ca.23671, indexed in Pubmed: 32808702.

4. Jenkins S, Iwanaga J, Dumont AS, et al. What is the suboccipital nerve? Tracking this confusing historical nomenclature. Morphologie. 2021; 105(348): 10-14, doi: 10.1016/j. morpho.2020.09.002, indexed in Pubmed: 33172783.

5. Knott JF. On abnormalities in human myology. Proceedings of the Royal Irish Academy. 1883; 3: 407-427.

6. Le Double AF. Atloïdo-mastoïdien. Traité des variations du système musculaire de l'homme et de leur signification au point de vue de l'anthropologie zoologique. 1897; 1: 240-241.

7. Lee RA. What is known about the atalantomastoid muscle: a scoping review. Queen's University. 2021: 16-40.

8. Lewis $\mathbf{W H}$. The cartilaginous skull of a human embryo twenty-one millimeters in length. Contributions to Embryology. 1920; 9: 299-324.

9. Mori M. Statistics on the musculature of the Japanese. Okajimas Folia Anat Jap. 1964; 40(3): 195-300, doi: 10.2535/ofaj1936.40.3_195.

10. Tubbs RS, Shoja M, Loukas M. Bergman's Comprehensive Encyclopedia of Human Anatomic Variation. Wiley 2016.

11. Winslow JB. Exposition anatomique de la structure du corps humain. G Desprez \& J Desessartz 1732.

12. Żytkowski A, Tubbs R, Iwanaga J, et al. Anatomical normality and variability: Historical perspective and methodological considerations. Trans Res Anat. 2021; 23: 100105 , doi: 10.1016/j.tria.2020.100105. 